\title{
Analysis of Phytochemicals in Petroleum Ether Leaves Extract from Abutilon Pannosum and Grewia Tenax by Liquid Chromatography/ Quadrupole Time-of-Flight Mass Spectrometry (LC/Q-TOF-MS) after Continuous Hot Percolation Successive Soxhlet Extraction
}

\author{
Mital K. Aadesariya ${ }^{1}$, Vijay R. Ram ${ }^{1}$, Pragnesh N. Dave ${ }^{1^{*}}$ \\ ${ }^{1}$ Department of Chemistry, KSKV Kachchh University, Bhuj, Kachchh- 370001 \\ *Department of Chemistry, Sardar Patel University, Vallabh Vidynagar-388 120, Gujarat, India
}

*Corresponding Author: Pragnesh N. Dave, Department of Chemistry, Sardar Patel University, Vallabh Vidynagar-388 120, Gujarat, India

\begin{abstract}
Purpose of the present study was to carry out extraction, isolation and identification of phytochemical constituents present in leaves extracts of Abutilon pannosum and Grewia tenax collected from Kachchh region, Gujarat by use of Liquid Chromatography Quadrupole Time of Fight Mass Spectrometry (Q-TOF LC/MS). Successive extraction of plant leaves was undertaken by Soxhlet extractor using petroleum ether $\left(35-60^{\circ} \mathrm{C}\right)$ as a solvent. Crude petroleum ether extracts were injected in Q-TOF LC/MS instrument for isolation and identification of useful phytochemicals. The result of phytochemical analyses showed that there are very important phytochemicals found in petroleum ether extracts of A. pannosum leaves like Alkaloids, fatty acids, sterol lipid, heterocyclic compound and G. tenax leaves have Fatty acid, alkaloid, flavonoid, terpenoid, sterol lipid and heterocyclic compound, cannabinoid, carotenoid etc and other medicinal activity. Thus, petroleum ether extract of G. tenax leaf gives good medicinal activity compared to the petroleum ether of A. pannosum leaf part. In this study, the G. tenax petroleum ether extract have greatest number of bioactive compounds.
\end{abstract}

Keywords: Abutilon pannosum, Grewia tenax, Q-TOF LC/MS, Phytochemicals, Petroleum ether extract, Soxhlet extraction

\section{INTRODUCTION}

Diverse plants have been used in different parts of the world to treat of human diseases and infections. ${ }^{[1,2,3]}$ Plants are used medicinally in different countries and are a source of different potential and powerful drugs. ${ }^{[4]}$ The phytochemicals constituents are responsible for medicinal activity of plant species. The phytochemicals are group into two important classes. ${ }^{[5]}$ Primary components which include amino acids, common sugars, proteins and chlorophyll etc. and secondary components consisting of alkaloids, essential oils, flavonoids, tannins, terpenoids, saponins, phenolic composites etc. ${ }^{[6]}$ The qualitative analysis as well as quantification of phytochemical constituents of a medicinal plant is considered to be a vital step in any kind of medicinal plant research. ${ }^{[6]}$

\subsection{Abutilon Pannosum}

Abutilon is one of the fundamental genuses of malvaceae family, commonly known as khapat. ${ }^{[7]}$ Various species of the genus Abutilon is used in local medicines for the treatment of various ailments. Among this, Abutilon pannosum, is an under shrub and is distributed in India, Pakistan, Tropical Africa, China and Arabia. ${ }^{[8]}$ We were focused in kachchh district region species. The leaves of $A$. pannosum were used as adjunct to medicines used for stack complaints. The plant contains mucilage, tannins asparagines, Gallic acid and sequiterpens. Its extract is also used in relieving thirst, in treating bronchitis, diarrhea, gonorrhea and inflammation of the bladder and in reducing fever. In addition, it is used in cleaning wound and ulcer, treating vaginal infection, diabetics, hemorrhoids and can also use as an anemia. ${ }^{\text {9] }}$ 
Analysis of Phytochemicals in Petroleum Ether Leaves Extract from Abutilon Pannosum and Grewia Tenax by Liquid Chromatography/ Quadrupole Time-of-Flight Mass Spectrometry (LC/Q-TOF-MS) after Continuous Hot Percolation Successive Soxhlet Extraction

\subsection{Grewia Tenax}

Grewia tenax is one of the important genus of Tiliaceae family, commonly known as Gangeti a valuable plant species in kachchh. ${ }^{[10]}$ The plant has high medicinal values and is widely used for the treatment of various common diseases. ${ }^{[11]}$ Roots are used to treat against jaundice, pulmonary infections and asthma. ${ }^{[11]}$ Leaves are used against trachoma, tonsillitis infections and are used as a poultice to treat swelling and an alcoholic extract ointment was reported to help in faster wound healing. ${ }^{[11]}$ Fruits are small berries, round, orange sweetened and it may be consumed either fresh or dried. [12] The plant preparations are used for the treatment of bone fracture and for bone strengthening. ${ }^{[13]}$

\section{MATERIALS AND METHODS}

\subsection{Collection of Plant Samples}

This study was conducted in October 2016. Leaves of Abutilon pannosum and Grewia tenax were collected from farm of padmavati temple, Asambiya road and Punitvan Bhuj respectively.

\subsection{Preparation of Samples}

The fresh, healthy plant leaves of Abutilon pannosum and Grewia tenax were washed with water to remove dirt and foreign materials and properly dried in shade for 2-3 weeks. Finally, crunchy leaves were pulverized in a mortar grinder, sieved through mesh screen and stored in air tight bag.

\subsection{Materials Required}

Abutilon pannosum and Grewia tenax leaf powder, petroleum ether, RBF (round bottom flask), condenser, heating mantle, measuring flask and thimble.

\subsection{Preparation of Extracts}

$15 \mathrm{gm}$ of leaf powder was extracted with 2-3 litre of petroleum ether $\left(60^{\circ}-64^{\circ} \mathrm{c}\right) 95 \%$ using soxhlet apparatus by continuous hot percolation method. After extraction, it was filtered and the removal of solvent was done under pressure by distillation process. Extract were collected in air tight glass tube. The prepared extract dissolve in $0.9 \mathrm{ml}$ methanol and $0.1 \mathrm{ml} 0.1 \%$ formic acid in glass tubes, for detection of the investigated compounds was achieved using a quadrupole coupled to time-of-flight analyzer (Q-TOF-MS 6540, Agilent Technologies, UHD). The mass spectrometry was equipped with an ESI Jet Stream source; identification and determination of the investigated drug was carried out in the SCAN mode.

\subsection{LC-Q-TOF-MS Method}

The separation of the analysts was carried out using an Agilent LC-Q-TOF-MS 6540, UHD.

\subsubsection{LC-Parameter}

The injected sample volume was $10 \mu \mathrm{L}$; Mobile phases A and B were water and acetonitrile with $0.1 \%$ formic acid, respectively. The flow rate was $0.6 \mathrm{~mL} / \mathrm{min}$. A 16 min run time was used after each analysis. The optimized chromatographic method held the initial mobile phase composition $(10 \% \mathrm{~B})$ constant for 0 min, followed by a linear gradient to $100 \%$ B after 14 min. and return back (10\% B) at 14 min. the system featured a binary pump and vacuum degasser, well-plate auto sampler with a sixport micro-switching valve, a thermo stated column compartment. Samples were loaded onto a Reprosil C18 column $(2.0 \mathrm{~mm} \times 150 \mathrm{~mm}, 2.5 \mu \mathrm{m}$ - Dr Maisch, Germany) for metabolite separation.

\subsubsection{Q-TOF Parameter}

The LC system was connected to an Agilent 6450 ultra-high definition quadrupole time-of-flight mass spectrometer equipped with dual electro spray Jet Stream Technology operating in positive ion mode. The operating parameters were as follows: capillary voltage: $4000 \mathrm{~V}$; nebulizer pressure: $45 \mathrm{psi}\left(\mathrm{N}_{2}\right)$; drying gas: $8 \mathrm{~L} / \mathrm{min}$; gas temperature: $325^{\circ} \mathrm{C}$; nozzle voltage: $1000 \mathrm{~V}$; fragment or voltage: $150 \mathrm{~V}$; skimmer voltage: $65 \mathrm{~V}, \mathrm{~m} / \mathrm{z} ; 100$ to 1700 , sheath gas temp $350^{\circ} \mathrm{C}$ and sheath gas flow $11 \mathrm{~L} \mathrm{~min}^{-1}$. The data recorded was processed with Agilent Mass Hunter software. Accurate mass measurements of each peak from the total ion chromatograms were obtained by means of an automated calibrant delivery system using a low flow of a calibrating solution (Calibrant solution A, Agilent Technologies, Santa Clara, CA, USA). 


\section{RESULT}

\subsection{A. pannosum Petroleum Ether Extract}

Table I represents petroleum ether extract of A. pannosum. It gives fatty acid, alkaloid, flavonoid, sterol lipid and heterocyclic compound.

\subsection{G. tenax Petroleum Ether Extract}

Table II represents petroleum ether extract of G. tenax. It gives Fatty acid, alkaloid, flavonoid, terpenoid, sterol lipid and heterocyclic compound, cannabinoid, carotenoid, and also illustrate anticancer, antibiotic for veterinary use, anti-hemorrhagic, prothrombogenic, antibacterial activity, antimicrobial, antioxidant, anti-tumor, anti-emetic, anti-hyperalgesic, local anaesthetic effect intraderm, anti-inflammatory, antidiabetic activity, antidepressant activity, antihistamine and anticholinergic, fungicide, anticholinesterase, antitumor, and for asthma, Prevent allergic reactions, As conduct of certain types of autoimmune diseases, and other lung conditions, skin conditions, leukemia, multiple myeloma lymphoma, and asthma. It is similarly useful in vomiting and nausea, prevention and treatment of graft-versus-host disease following allogeneic bone marrow transplantation, in rubber synthesis, acaricidal and insecticidal, preparation of cosmetic and dermatological compositions. G. tenax gives highly medicinal value in petroleum ether extract its data is shown in below.

\section{DISCUSSION}

The secondary metabolites (phytochemicals) and other chemical constituents of medicinal plants account for their medicinal value. ${ }^{[106]}$ For example Flavonoids are phenolic compound and plant phenolics are a main group of compounds that act as antioxidant and free radical scavenger, which prevent oxidative cell damage and also have strong anticancer activity, ${ }^{[110]}$ it have been exposed to display their actions through effects on membrane permeability, and by inhibition of membranebound enzymes such as the ATPase and phospholipase A2. ${ }^{[111]}$ Flavonoids assist as health promoting composite as a results of its anion radicals. ${ }^{[12]}$ These notes sustenance the usefulness of this plant in folklore medicines in the treatment of stress connected diseases and as coverings for wounds usually encountered in circumcision rites, bruises, cuts and sores. ${ }^{[113,114]}$ Flavonoid, fatty acid, alkaloid, sterol lipid and heterocyclic compound were present in both plant leaf sample of petroleum ether extract. Cannabinoid, Carotenoid etc were present in only G. tenax leaf sample of petroleum ether extract. Cannabinoids were only present in G. tenax plant of petroleum ether extract. Cannabinoids are pharmacological agents which alleviate pain through a variety of receptor and non-receptor mechanisms including direct analgesic and anti-inflammatory effects, modulatory actions on neurotransmitters, and interactions with endogenous and administered opioids. Cannabinoid agents are currently available in various countries for pain treatment, and even cannabinoids of botanical origin may be approvable by FDA, although this is distinctly unlikely for smoked cannabis. ${ }^{[115,116]}$ Carotenoids may act as antioxidants and may exhibit chemo preventive anti atherosclerotic effects and anticancer effects. ${ }^{[117]}$ The above result also showed that $G$. tenax has anticancer, antibiotic for veterinary use, anti-hemorrhagic, prothrombogenic, antibacterial activity, antimicrobial, antioxidant, anti-tumor, anti-emetic, anti-hyperalgesic, local anaesthetic effect intraderm, anti-inflammatory, antidiabetic activity, antidepressant activity, antihistamine and anticholinergic, fungicide, anticholinesterase, antitumor, and for asthma, Prevent allergic reactions, As usage of certain kinds of skin conditions, other lung conditions, autoimmune diseases, and asthma leukemia, multiple myeloma, and lymphoma etc. So it can be derived that the G. tenax petroleum ether extract has the maximum number of bioactive compounds.

\section{CONCLUSION}

The present study was prepared on extraction isolation and identification of phytochemical from leaf petroleum ether extract of $A$. pannosum and G. tenax by using LC-Q-TOF-MS. The presence of phytoconstituents make the plant useful for treating different ailments and have a potential of given that helpful drugs of human as well as veterinary use. In the present study, we have found that most of the biologically active phytochemicals were present in the petroleum ether extracts of G. tenax compare to A. pannosum of leaf part. Thus, G. tenax give good medicinal activity compared to the $A$. 
Analysis of Phytochemicals in Petroleum Ether Leaves Extract from Abutilon Pannosum and Grewia Tenax by Liquid Chromatography/ Quadrupole Time-of-Flight Mass Spectrometry (LC/Q-TOF-MS) after Continuous Hot Percolation Successive Soxhlet Extraction

pannosum. Since the petroleum ether extract of leaf contains more constituents, it can be considered beneficial for further investigation. The phytochemical investigation of that medicinal plants are also significant and have profitable attention in both pharmaceuticals companies for the manufacturing of the new drugs for treatment of various diseases and research institutes. Thus it can be predictable that the vital phytochemical properties recognized by this study on native plant of Kachchh region will be useful against diverse diseases.

\section{ACKNOWLEDGEMENT}

We would like to thank the KSKV Kachchh University (Bhuj), Department of Chemistry to permit for this work. We would also thank to Junagadh Agriculture Food Testing Laboratory for providing facility for this work and guidance.

\section{REFERENCES}

[1] Caceres, A.L., Lopez, B.R., Giron, M.A., Logemann, H.; Plants used in Guatemala for the treatment of dermatophytic infection in Screening for antimycotic activity of 44 plant extracts. Journal of Ethnopharmacology, (1991); 31: 263- 276.

[2] Nweze, E.L., Okafor, J.I., Njoku, O.; Antimicrobial activities of methanolic extracts of Tremaguineensis (Schumm and Thorn) and Morinda Lucida Benth used in Nigeria. Biological Research, (2004); 2(1): 3946.

[3] Vineela, C.H., Elizabeth, K.M.; Antimicrobial activity of marine algae of Visakhapatnam city, Andhra Pradesh. Asian Journal of Microbiology, Biotechnology \& Environmental Science, (2005); 7(2): 209-212.

[4] Srivastava, J., Lambert, J., Vietmeyer, N.; Medicinal Plants: An expanding role in development. World Bank Technical Paper, (1996); 320.

[5] Adedapo, A., Jimoh, F., Koduru, S., Masika, J. and Afolayan, A.; Assessment of the medicinal potentials of the methanol extracts of the leaves and stems of Buddleja saligna. BMC Complementary and Alternative Medicine, (2009); 9-21. doi:10.1186/1472-6882-9-21

[6] Shrivastava, N., Patel, T.; Clerodendrum and Heathcare: An Overview. Medicinal and Aromatic Plant Science and Biotechnology, (2007); 1(1): 142-150.

[7] Nasir, E., Ali, S.I., Flora of West Pakistan, Malvaceae, Department of Botany, University of Karachi, (1979); 130: 69-72.

[8] Bagi, M.K., Kalyani, G.A., Denis, T.J., Kumar, K.A., Kakrani, H.K., A preliminary pharmacological screening of Abutilon indicum: II Analgesic activity. Fitoterapia, (1985); 56: 169-171.

[9] Anup, A.; Pharmacognostic studies of stem of abutilon pannosum (forst f.), Bioscience Discovery, Nov., (2012); 3(3): 317-320.

[10] Habiba, U., Anwar, M., Hussain, I., Rais, M.; Population density and habitat status of punjab urial (ovis vignei punjabiensis) in diljabba-domeli game reserve, punjab Pakistan. JAPS,-Journal-of-Animal-andPlant-Sciences, (2015); 25(3): 650-655.

[11] Aboagarib, E., Yang, R., Hua, X., and Siddeeg, A.; Chemical compositions, nutritional properties and volatile compounds of Guddaim (Grewia tenax. Forssk) Fiori Fruits. J. Food Nutrit. Res., (2014); 2(4): 187-192.

[12] El Ghazali GEB, El Tohami MS, El Egami AAB, Abdalla WS, Mohammed MG. Medicinal plants of the Sudan. In: Medicinal plants of northern Kordofan. Omdurman Islamic University Printing and Publishing House, Omdurman. 1997.

[13] Khemiss, F., Ghoul-Mazgar, S., Moshtaghie, A., and Saidane, D.; Study of the effect of aqueous extract of Grewia tenax fruit on iron absorption by everted gut sac. Journal of Ethnopharmacology. (2006); 103(1): 90-98. doi:10.1016/j.jep.2005.07.017

[14] ISOCHEM. (2016) Furfural diethyl acetal http://isochem.eu/product/furfural-diethyl-acetal (accessed July, 1, 2017).

[15] Srinivasan, K., Sivasubramanian, S., Kumaravel, S.; Phytochemical profiling and GC-MS study of Adhatoda vasica leaves. Int J Pharm Bio Sci, (2013); 5(1): 714-720.

[16] Munisankar, S., Perumal, P., Subramaniam, S., Erenius, T., Natesan, P., Savarimuthu, I.; Lipolytic and antiadipogenic effects of (3, 3-dimethylallyl) halfordinol on 3T3-L1 adipocytes and high fat and fructose diet induced obese C57/BL6J mice. European Journal of Pharmacology, (2014); 740: 714-721. http://dx.doi.org/10.1016/j.ejphar.2014.06.004

[17] Mangala, D., Aboo, S., Randhir, S., Kapil, S., Popli, P.; New alkaloids from Aegle marmelos. Central Drug Research Institute, (1978); 17 (10): 814-1815. 
Analysis of Phytochemicals in Petroleum Ether Leaves Extract from Abutilon Pannosum and Grewia Tenax by Liquid Chromatography/ Quadrupole Time-of-Flight Mass Spectrometry (LC/Q-TOF-MS) after Continuous Hot Percolation Successive Soxhlet Extraction

[18] Emma, S., Duangchan S., Elizabeth, H., Zoe, U., David, F., Richards, G., and Catherine, M.; 1a, 25dihydroxyvitamin D3 in combination with transforming growth factor-b increases the frequency of Foxp3+ regulatory T cells through preferential expansion and usage of interleukin-2. Immunology, (2014); 143: 52-60. doi:10.1111/imm. 12289

[19] Scott, P.R.; Efficacy of strategic tilmicosin injection during an outbreak of respiratory disease in housed beef calves. British Veterinary Journal, (1995); 151: 587-589.

[20] Mary, E., Niketa, J., John M.; Phosphatidylinositol biosynthesis: Biochemistry and regulation. Biochimica et Biophysica Acta, (2005); 1735: 89-100. doi:10.1016/j.bbalip.2005.05.006

[21] LMSD. (2017) LMGP10010026 http://www.lipidmaps.org/data/LMSDRecord.php?LMID=LMGP10010 026 (accessed July, 1, 2017).

[22] Laqueur, G., and Spatz, M.; Toxicology of Cycasin. Cancer Res., Nov.(1968); 28: 2262-2267.

[23] Cavanna, M., Parodi, S., Taningher, M., Bolognesi, C., Sciaba L., and Brambilla, G.; DNA Fragmentation in Some Organs of Rats and Mice Treated with Cycasin. Br. J. Cancer (1979), 39: 383.

[24] CHEMEO. (2017) Chemical Properties of N-(2-Methyl-2-propyl)ethanamide (CAS 1540-94-9) https://www.chemeo.com/cid/12-160-0/N-\%282-Methyl-2-propyl\%29ethanamide (accessed July, 1, 2017).

[25] Davis, W., Lamson, M., and Steven M.; The Anticancer Effects of Vitamin K. Alternative Medicine Review, (2003); 8(3): 307.

[26] Rajiv, K., Neil, B., and Adrian, V.; Effect of phylloquinone supplementation on glucose homeostasis in humans. Am J Clin Nutr, (2010); 92: 1528-1532. doi: 10.3945/ajcn.2010.30108

[27] Koivu, T., Piironen, V., \& Mattila, P.; Phylloquinone (vitamin K1) in cereal products. Cereal Chem. (1998); 75: 113-116.

[28] Catherine, K., Anastasia, K., Maria, C., Gennaro, P., Lorenzo, di B. and Helen, S.; Polar Constituents from the Aerial Parts of Origanum vulgare L. Ssp. hirtum Growing Wild in Greece. J. Agric. Food Chem., 2006; 54(15): 5388-5392. doi: 10.1021/jf061477i

[29] Teruhiko, Y., El-Sayed, A., Omer, H., Sadao, S., Yoshio, K. and Yasunori, K., Structure of a Tuberinducing Stimulus from potato leaves. Agric. Biol. Chem., (1989); 53 (10), 2835-2837.

[30] Gressani, K., Rollins, L., Leone-Kabler, S., Cline J., Miller M.; Induction of mutations in Ki-ras and INK4a in liver tumors of mice exposed in utero to 3- methylcholanthrene. Carcinogenesis, (1998); 19: 1045-52.

[31] Jody, A., Lugger, and Rint, P.; Easily Accessible Thermotropic Hydrogen-Bonded Columnar Discotic Liquid Crystals from Fatty Acid - Tris-Benzoimidazolyl Benzene Complexes. (2016); 00: 1-6. doi: 10.1002/open.201600078

[32] Malu, S., Obochi, G., Tawo, E., and Nyong, B.; Antibacterial activity and medicinal properties of ginger (zingiber officinale). Global journal of pure and applied sciences, 2009; 15 (3): 365-368.

[33] Shubha, R.; Medicinal uses of ginger (Zingiber officinale Roscoe) improves growth and enhances immunity in aquaculture. International Journal of Chemical Studies, (2015); 3(2): 83-87.

[34] LMSD. (2017) LMFA01040061 http://www.lipidmaps.org/data/LMSDRecord.php?LMID=LMFA010400 61 (accessed July, 1, 2017)

[35] Volker, W., Susanne, F., Rosli, H., Ulrich, M., Stefan, S.; Fine Tuning of Social Integration by Two Myrmecophiles of the Ponerine Army Ant, Leptogenys distinguenda. J Chem Ecol (2009); 35: 355-367 doi 10.1007/s10886-009-9606-8

[36] HMDB. (2017) MG(0:0/18:3(6Z,9Z,12Z)/0:0) http://www.hmdb.ca/metabolites/HMDB11539 (accessed July, 1, 2017)

[37] Ahmed, A., Seida, H., Dina, R., Abou-H., Fatma, M.; Investigation and isolation of the active constituents of petroleum ether fraction of Medicago sativa L. sprouts. International Current Pharmaceutical Journal, May 2013; 2(6), 109-111. doi: 10.3329/icpj.v2i6.14870

[38] KEGG. (2017) Compound: C15105. http://www.genome.jp/dbget-bin/www_bget?cpd:C15105 (accessed July, 1, 2017)

[39] LMSD. (2017) LMFA07010328. http://www.lipidmaps.org/data/LMSDRecord.php?LMID=LMFA07010 328 (accessed July, 1, 2017)

[40] CAYMANCHEM. (2012) AB-005 (11766). https://www.caymanchem.com/pdfs/11766.pdf (accessed July, 1, 2017) 
Analysis of Phytochemicals in Petroleum Ether Leaves Extract from Abutilon Pannosum and Grewia Tenax by Liquid Chromatography/ Quadrupole Time-of-Flight Mass Spectrometry (LC/Q-TOF-MS) after Continuous Hot Percolation Successive Soxhlet Extraction

[41] Paul, L., Brian, E.; Quantitation of 3'-hydroxypentobarbital in serum using high-performance liquid chromatography. Journal of Chromatography, (1983), 275: 107-114. doi.org/10.1016/S0378-4347(00) 84349-2

[42] CHEBI: 82536 - Sudan Brown RR. (2017). http://www.ebi.ac.uk/chebi/searchId.do?chebiId=CHEBI:82 536 (accessed July, 1, 2017)

[43] Brown, C., and Craft, J.; N, N'-Dinitrosopentamethylenetetramine, ${ }^{*} \mathrm{C}_{5} \mathrm{H}_{10} \mathrm{~N}_{6} 0_{2}$, Acta Cryst. (1983), C39: 1132-1133. doi.org/10.1107/S0108270183007659

[44] KEGG. (2017) Compound: C11604. http://www.genome.jp/dbget-bin/www_bget?C11604 (accessed July, 1, 2017)

[45] Jacqueline, C., Bede and Stephen S.; Activity of insect juvenile hormone III: seed germination and seedling growth studies. Chemoecology, (2000); 10(2): 89-97. dio. 10.1007/s000490050012

[46] Salles, H., and Cruz-landim, C.; Effect of the Juvenile Hormone on the Development of the Mandibular Gland in Workers' Pupae of Apis Mellifera L. (Hymenoptera, Apidae), Braz. J. Biol., (2004), 64(3B): 691-695.

[47] Salik, H., Sonja, B., Armelle, B., Rodolphe, H., Leen, C., Thomassen, J., Johan, A., Martens, M., Annick, B., Jocelyne, F., Frédéric, M., Jean-Claude, P., Francelyne, M.; Oxidative stress and proinflammatory effects of carbon black and titanium dioxide nanoparticles: Role of particle surface area and internalized amount. Toxicology, (2009) ; 260:142-149 doi:10.1016/j.tox.2009.04.001

[48] Takeuchi, H., Chen, J., O'Reilly D.; Regulation of ecdysteroid signalling: molecular cloning, characterization and expression of 3-dehydroecdysone 3 alpha-reductase, a novel eukaryotic member of the short-chain dehydrogenases/reductases superfamily from the cotton leafworm, Spodoptera littoralis. Biochem J., (2000); 349: 239-245.

[49] CHEBI: 79811- 17,21-Epoxy-9-fluoro-11beta-hydroxypregn-4-ene-3,20-dione (2017) http://www.ebi.ac. uk/chebi/searchId.do?chebiId=CHEBI:79811 (accessed July, 1, 2017)

[50] Faiza, M., Tabassum, J.; Temporal population growth of Lahore. Journal of Scientific Research, june 2009; XXXIX (2), 54-58.

[51] Fowler, L., Valenta, Z., Weisner, K.; Structure of chaksine. Chem. Ind., (1962); 2: 95-96.

[52] Siddiqui, S., Ahmad, S., Proc Ind. Alkaloids from the seeds of Cassia absus, Linn. Acad. Sci: 1935; 2A (5): 421-425. doi: 10.1007/BF03046884

[53] Hanada, K., Tamai, M., Yamagishi, M., Ohmura, S., Sawada, J. and Tanaka, I.; Isolation and characterization of E-64, a thiol protease inhibitor. Agric. Biol. Chem. (1978); 42: 523-528.

[54] Ross, S., and Pelletier, S.; New synthesis derivatives of aconitine, delphonine and N-deacetyllappaconitine. Heterocycles, (1991); 32 (7): 1307-1315.

[55] Nguyen, L., Senge, M. and Smith. K.; Simple Methodology for Syntheses of Porphyrins Possessing Multiple Peripheral Substituents with an Element of Symmetry. J. Org. Chem., 1996; 61(3), 998-1003. doi: 10.1021/jo951870f

[56] Maria, G., Neves M., Augusto C. Tomé, Artur M. S. Silva, Maria A. F. Faustino, Paula S. Lacerda, Ana M. G. Silva, Porphyrin derivatives: Synthesis and potential applications. J. Heterocyclic chemistry, (2000); 37: 527. DOI: 10.1002/jhet.5570370310

[57] José, A., and Kevin, M.; Porphyrin Synthesis. Rev. Port. Quím., (1989); 31: 29.

[58] Oleg, A., Golubchikov and Tatjana A.; Symposium on Applications of Porphyrins in Medicine and the Fourth School for Young Scientists on the Chemistry of Porphyrins and Related Compounds Ivanovo 2000. Molecules, (2000), 5: 1461-1514.

[59] Dzhagarov, B., Kruk, N., Chirvony, V., Galievsky, V., Turpin, P.; "Advances in Porphyrin Chemistry", V.2., SPb., St-Petersburg University, 1999, 50-69.

[60] Solomun, L.; Methylprednisolone and its related substances in freeze-dried powders for injections. J. Serb. Chem. Soc. (2010); 75 (10): 1441-1452 doi: 10.2298/JSC100115087S

[61] William, F., Rebecca L., Stanley J., Szefler and William J.; 6 Methylprednisolone and 6cwMethylprednisone Plasma Protein Binding in Humans and Rabbits. Journal of Pharmaceutical Sciences, August (1986); 75(8): 760-763.

[62] Bohlman, F., Zdero, C.; Thiophene and Its Derivatives; Gronowitz, S., Ed.; John Wiley \& Sons, Ltd.: Chichester, UK, (1986); 3: pp- 261-323.

[63] KEGG. (2017) Compound: C09685 http://www.genome.jp/dbget-bin/www_bget?cpd:C09685 (accessed July, 1, 2017) 
Analysis of Phytochemicals in Petroleum Ether Leaves Extract from Abutilon Pannosum and Grewia Tenax by Liquid Chromatography/ Quadrupole Time-of-Flight Mass Spectrometry (LC/Q-TOF-MS) after Continuous Hot Percolation Successive Soxhlet Extraction

[64] Jocelyn, G., Millar, J., Steven, M., Carmen, R., \& Marta, V., Neus, M., \& Carlos, L.; Identification of the Sex Pheromone of a Protected Species, the Spanish Moon Moth Graellsia isabellae. J Chem Ecol (2010); 36: 923-932. doi 10.1007/s10886-010-9831-1

[65] Robert, A. Creelman and John, E.; Biosynthesis and Action of Jasmonates in Plants. Annu. Rev. Plant Physiol. Plant Mol. Biol., (1997); 48: 355-381.

[66] Gharge, D., Pavan, T., Sunil, B., Dhabale, P.; Hyperforin as a natural antidepressant: an overview. Journal of Pharmacy Research, (2009); 2(9): 1373-1375.

[67] Szegedi, A., Kohnen, R., Dienel, A., Kieser, M.; Acute treatment of moderate to severe depression with hypericum extract WS 5570 (St John's wort): randomised controlled double blind non-inferiority trial versus paroxetine. British Medical Journal Mar (2005); 330: 503-7.

[68] FDB012313. (2015) 2-Angeloyl-9-(3-methyl-2E-pentenoyl)-2b, 9a-dihydroxy-4Z, 10(14)-oplopadien-3one. http://foodb.ca/compounds/FDB012313 (accessed July, 1, 2017)

[69] Huang, X., and Regnier, F., Differential metabolomics using stable isotope labeling and two-dimensional gas chromatography with time-of-flight mass spectrometry. Anal. Chem (2008); 80: 107-114.

[70] HMDB. (2017) PE (20:5(5Z,8Z,11Z,14Z,17Z)/22:1(13Z)) (HMDB09469) http://www.hmdb.ca/metabo lites/HMDB09469 (accessed July, 1, 2017)

[71] Evaluation of certain food additives and contaminants (Seventy-third report of the Joint FAO/WHO Expert Committee on Food Additives). WHO Technical Report Series, No. 960, 2011.

[72] González, G., Bazzocchi, I., Moujir L., Jiménez, I.; Ethnobotanical uses of celastraceae. Bioactive metabolites. Studies in Natural Products Chemistry: Elsevier Science Publisher, Amsterdam, Vol. 23, p. 649; 2000 doi.org/10.1016/S1572-5995(00)80140-4

[73] Noboru, K., and Susumi, H., Synthesis of 1 $\alpha$, 25-Dihydroxy-2 $\beta$-(3-hydroxypropoxy) - vitamin D3 (Eldecalcitol) and Related Compounds by the Trost Convergent Methodology. Heterocycles, (2009); 79: 145.

[74] Afifi, N., Ramadan, A., El-Kashoury, E., El-Banna, H., Some pharmacological activities of essential oils of certain umbelliferous fruits. Vet Med J Giza. (1994); 42(3): 85-92.

[75] Daunderer-Klinisch,Toxikologie - 109. Erg.-Lfg. 9/96 1-2. http://toxcenter.org/stoff-infos/c/chinomethio nat.pdf. (accessed July, 1, 2017)

[76] Shinichi, T., Mari, M., and Takashi M.; Presence of Free Myxol and 4-Hydroxymyxol and Absence of Myxol Glycosides in Anabaena variabilis ATCC 29413, and Proposal of a Biosynthetic Pathway of Carotenoids. Plant Cell Physiol. 2006; 47(2), 211-216. doi:10.1093/pcp/pci236

[77] Balapure, A., Rexroad, C., Kawada, K., et al. Structural requirements for prostaglandin analog interaction with the ovine corpus luteum prostaglandin F2 $\alpha$ receptor. Biochemical Pharmacology (1989), 38: 23752381.

[78] Anna, M., Cristiana, M., Angelo D’A., Lello Z.; Red Blood Cell Lipidomics analysis through HPLC-ESIqTOF: application to red blood cell storage. JIOMICS June 2013; 3(4): 11-24. DOI: 10.5584/ jiomics. v3i1.123

[79] Ashwani, M., and Rajesh, D., Detection of New Human Metabolic Urinary Markers in Chronic Alcoholism and Their Reversal by Aqueous Extract of Tinospora cordifolia Stem. Alcohol and Alcoholism, (2015); 50(3): 271-281 doi: 10.1093/alcalc/agv012

[80] Warwick, B., Dunn, M., Stephanie, A., Worton, K., Rebecca, L., Douglas, B., Kell, A. and Heazell, P.; The metabolome of human placental tissue: investigation of first trimester tissue and changes related to preeclampsia in late pregnancy. Metabolomics (2012); 8: 579-597. doi 10.1007/s11306-011-0348-6

[81] Nadja, C., Erik, L., Grégory, G., Mohamed, M., Philippe, A., Olivier, P.; Steroidal glycosides from the marine sponge Pandaros acanthifolium. Steroids, (2009); 74: 746-750. doi:10.1016/j.steroids.2009.03.009

[82] PubChem. (2017) PG (16:0/16:0). https://pubchem.ncbi.nlm.nih.gov/compound/446440\#section=Top (accessed July, 1, 2017)

[83] Marilza, S., Jamile, F., Cossolin, S., Mônica, J., Pereira, Antônio, E., Sant’Ana, G., Milena, D., José, C., and José E.; Larvicidal and Cytotoxic Potential of Squamocin on the Midgut of Aedes aegypti (Diptera: Culicidae). Toxins, (2014); 6: 1169-1176; doi:10.3390/toxins6041169

[84] Chong-Ren, Y., Ying, Z., Melissa, R., Shabana I., Ying-Jun, Z., and Xing-Cong, Li., Antifungal Activity of C-27 Steroidal Saponins. Antimicro. Agents and Chemo., May (2006); 50 (5); 1710-1714. doi:10.1128/AAC.50.5.1710-1714.2006

[85] Wu, F., Gu, Z., Zeng, L., Zhao, G., Zhang, Y., McLaughlin, J., Sastrodihardjo, S.; Two new cytotoxic monotetrahydrofuran annonaceous acetogenins, annomuricins a and $b$, from the leaves of Annona muricata. J. Nat. Prod. (1995); 58: 830-836. 
Analysis of Phytochemicals in Petroleum Ether Leaves Extract from Abutilon Pannosum and Grewia Tenax by Liquid Chromatography/ Quadrupole Time-of-Flight Mass Spectrometry (LC/Q-TOF-MS) after Continuous Hot Percolation Successive Soxhlet Extraction

[86] Jaramillo, M., Arango, G., Gonzalez, M., Robledo, S., Velez, I.; Cytotoxicity and antileishmanial activity of Annona muricata pericarp. Fitoterapia (2000); 71: 183-186.

[87] CHEBI: 79888 (2017) 1-Dehydro-9-fluoro-11-oxotestololactone. http://www.ebi.ac.uk/chebi/searchId.do? chebiId=CHEBI:79888(accessed July, 1, 2017)

[88] LMSD. (2017) LMGP04010069. http://www.lipidmaps.org/data/LMSDRecord.php?LMID=LMGP0401 0069(accessed July, 1, 2017)

[89] Han, L., Chen, K.; Progress of experimental pharmacologic study on the effect of Astragalus on the cardiac vascular system. Chin. J. Integr. Med., (2000); 20: 234-237.

[90] Masao N., Yoshiki H. and Kiyoshi I.; The absolute configurations of athamantin and edultin. Tetrahedron Letters, (1966); 7 (39): 4735-4738. doi.org/10.1016/S0040-4039 (00)72934-0.

[91] Martínez-A, A., Parra-Hernández, E., Madrigal-Bujaidar, E., Chamorro-Cevallos G., Carvajal-Sandoval, G., and Zamudio-Cortes P.; Reduction of all-trans retinoic acid-induced teratogenesis in the rat by glycine administration. Birth Defects Res. A. (2006); 76(10): 731- 738.

[92] Masaaki, S., Makoto, M., Terutake, N., Ryu, H., Kyoji, F., Toshihisa, I. and Ryoji N., Chemical Implications for Antitumor and Antiviral Prostaglandins: Reaction of 47 -Prostaglandin A1 and Prostaglandin A1 Methyl Esters with Thiols. J. Am. Chem. Soc. (1997), 119: 2376-2385.

[93] Thiagarajan, H., Sivasami, P., Chidambaram, B., Bhakthavatsalam, M. and Rengarajulu, P.; Arjunolic acid: A novel phytomedicine with multifunctional therapeutic applications. Ind. Jrnl. Exp. Bio., (2010); 48: $238-247$.

[94] Braja G. and Shaishab K., Arjunolic acid: A renewable template in supramolecular chemistry and nanoscience, Pure Appl. Chem., (2007); 79(11): 2031-2038. doi:10.1351/pac200779112031

[95] LMSD. (2017) LMGP06020024. http://www.lipidmaps.org/data/ LMSDRecord.php?LMID=LMGP06020 024 (accessed July, 1, 2017)

[96] Ana, P., Franz, B., Željan, M., Ana, M., Biljana N. and Nikola K.; Identification and Quantification of Flavonoids and Phenolic Acids in Burr Parsley (Caucalis platycarpos L.), Using High-Performance Liquid Chromatography with Diode Array Detection and Electrospray Ionization Mass Spectrometry. Molecules, (2009); 14: 2466-2490; doi:10.3390/molecules14072466

[97] Stavric, B.; Quercetin in our diet: from potent mutagen to probable anti-carcinogen. Clin. Biochem. (1994); 27: 245-248.

[98] Minpei, K., Yoshihiro, M., Kazutomo, O., Hiroshi, S. and Yutaka S.; 27-Norlanostane Glycosides from the Bulbs of Muscari paradoxum. J. Nat. Prod. (2004); 67: 2099-2103. Dio: 10.1021/np0401359

[99] Tomotaka, T., Tada-Aki, E., Hironori, S., Hideto, S., Shushi, H., Takeshi I., Kyu-Ichiro, O. and Toshiaki S.; Newly Established Assay Method for 25-Hydroxyvitamin D3 24-Hydroxylase Revealed Much Lower $\mathrm{Km}$ for 25-Hydroxyvitamin D3 than for 1a,25-Dihydroxyvitamin D3. Journal of Bone and Mineral Research, (2001); 16(1): 57-62.

[100] YMDB13426. (2017) PA (14:0/14:1(9Z)). http://www.ymdb.ca/compounds/YMDB13426 (accessed July, $1,2017)$

[101] LMSD. (2017) LMFA01090060. http://www.lipidmaps.org/data/LMSDRecord.php?LMID=LMFA010 90060 (accessed July, 1, 2017)

[102] Shi-Yie, C., Ya-Chiang, H., Zhi-Hong, W., Chi-Hsin, H., Shang-Kwei, W., Chang-Feng, D. and ChangYih, D.; New 19-oxygenated and 4-methylated steroids from the Formosan soft coral Nephthea chabroli., Steroids (2009); 74: 543-547. doi:10.1016/j.steroids.2009.02.004

[103] LMSD. (2017) LMFA01030891 http://www.lipidmaps.org/data/LMSDRecord.php?LMID=LMFA010 30891 (accessed July, 1, 2017)

[104] HMDB34617. (2017) (3b, 4b, 11b, 14b)-11-Ethoxy-3, 4-epoxy-14-hydroxy-12-cyathen-15-al 14-xyloside. http://www.hmdb.ca/metabolites/HMDB34617 (accessed July, 1, 2017)

[105] PubChem. (2017) N (6)-(Octanoyl) lysine. https://pubchem.ncbi.nlm.nih.gov/compound/13783498\# section=Top (accessed July, 1, 2017)

[106] Deutsch, D., Omeir, R. and Arreaza, G.; Methyl arachidonyl fluorophosphonate: A potent irreversible inhibitor of anandamide amidase. Biochemical Pharmacology, (1997); 53: 255-260.

[107] HMDB09493. (2017) PE (22:0/20:0). http://www.hmdb.ca/metabolites/HMDB09493 (accessed July, 1, 2017)

[108] LMSD. (2017) LMGP10010175 http://www.lipidmaps.org/data/LMSDRecord.php?LMID=LMGP1001 0175 (accessed July, 1, 2017) 
Analysis of Phytochemicals in Petroleum Ether Leaves Extract from Abutilon Pannosum and Grewia Tenax by Liquid Chromatography/ Quadrupole Time-of-Flight Mass Spectrometry (LC/Q-TOF-MS) after Continuous Hot Percolation Successive Soxhlet Extraction

[109] LMSD. (2017) LMGP03030080 http://www.lipidmaps.org/data/LMSDRecord.php?LMID=LMGP030300 80 (accessed July, 1, 2017)

[110] Li, H., Wang, Z., Liu, Y.; Review in the studies on tannins activity of cancer prevention and anticancer. Zhong-Yao-Cai. (2003); 26(6): 444-448.

[111] Hausteen, B., Flavonoids, a class of natural products of high pharmacological potency. Biochem Pharm, 1 Apr. (1983); 32(7), 1141-1148.

[112] Mathekga, A.D.M. Meyer J.J.M., Antimicrobial activity of Helichrysum species and the isolation of a new phloroglucinol from Helichrysum caespititium. University of Pretoria $\mathrm{PhD}$ thesis, Chemistry Department; 2001.

[113] Lourens, A., Reddy, D., Baser, K., Viljoen, A., Van V.; In vitro Biological activity and essential oil composition of four indigenous South African Helichrysum species. J Ethnopharmacol (2004); 95: 25358.

[114] Fergusion, L.; Role of plant polyphenols in genomic stability. Mutation Research, (2001); 475: 89-111. doi.org/10.1016/S0027-5107(01)00073-2

[115] Grierson, D. and Afolayan, A.; Antibacterial activity of some indigenous plants used for treatment of wounds in the eastern caps. S Afr J Ethnopharmacol, (1999); 66: 103-106.

[116] Deer, T., Leong, M., Buvanendran, A., Gordin, V., Kim, P., Panchal, S. and Ray, A.; Comprehensive Treatment of Chronic Pain by Medical, Interventional, and Integrative Approaches. American Academy of Pain Medicine, 2013.

[117] Salah, N., Miler, N., Pagange, G., Tijburg, L., Bolwell, G., Rice E, et al. Polyphenolic flavonoids as scavenger of aqueous phase radicals as chain breaking antioxidant. Arch Biochem Broph (1995); 2: 33946.

Citation: M. Aadesariya et al., "Analysis of Phytochemicals in Petroleum Ether Leaves Extract from Abutilon Pannosum and Grewia Tenax by Liquid Chromatography/ Quadrupole Time-of-Flight Mass Spectrometry (LC/Q-TOF-MS) after Continuous Hot Percolation Successive Soxhlet Extraction", International Journal of Advanced Research in Chemical Science (IJARCS), vol. 4, no. 10, pp. 44-52, 2017. http://dx.doi.org/10.20431/ 2349-0403.0410005

Copyright: (C) 2017 Authors. This is an open-access article distributed under the terms of the Creative Commons Attribution License, which permits unrestricted use, distribution, and reproduction in any medium, provided the original author and source are credited. 